\title{
PENGEMBANGAN APLIKASI DECISSION SUPPORT SYSTEM UNTUK KASUS MODEL INVENTORY
}

\author{
Eko Nur Hidayat ${ }^{1^{*}}$ \\ Program Studi Teknika Politeknik Bumi Akpelni \\ Jl. Pawiyatan Luhur II/17 Bendan Dhuwur Semarang \\ E-mail : ekonurhidayat@akpelni.ac.id
}

\begin{abstract}
Abstrak
Keakuratan data merupakan modal untuk membuat informasi yang sangat berguna bagi sebuah organisasi. Nilai data bisa sangat mahal jika bisa dijadikan sebuah informasi yang tepat sebagai dasar pengambilan keputusan. Pengadaan dan inventarisasi data merupakan salah satu hal yang perlu diperhatikan khususnya bidang logistic dalams ebuah organisasi. Oleh karena itu diperlukan suatu sistem dengan menggunakan metode tertentu yang dapat mendukung pengelolaan data pengadaan barang dan juga dapat membantu para manajer mengambil keputusan dalam melakukan control terhadap persediaan. Berdasarkan hal tersebut maka dapat dikembangkan sistem yang terintegrasi antara pengolahan data pengadaan dan jumlah pembelian barang yang menerapkan metode catatan persediaan seperti metode Classical Economic Order Quantity Model (EOQ Model) maupun Inventory Model with Planned Shortages. Metode yang digunakan adalah perancangan sistem untuk mendukung keputusan dalam menghitung jumlah persediaan agar menjadi optimal. Dengan menggunakan sistem pendukung keputusan, beberapa kesalahan terkait dengan pencatatan data pada pengadaan dan ketidakakuratan dalam menentukan jumlah persediaan dapat dikurangi sehingga perusahaan dapat menghindari kerugian material.
\end{abstract}

Kata Kunci: Decission Support System, Classical Economic Order Quantity Model, Inventory Model with Planned Shortages.

\section{PENDAHULUAN}

Dalam era globalisasi, perkembangan teknologi informasi di dunia berjalan cukup pesat. Globalisasi yang diartikan suatu proses menyatunya dunia yang meliputi berbagai bidang tata kehidupan dunia mengandung karakteristik adanya perubahan keterbukaan, kreativitas, kecanggihan, kecepatan, keterikatan, keunggulan, kekuatan dan kompetisi bebas (Efraim, Ephraim, \& James, 1999).

Salah satu jenis system aplikasi yang sangat popular di kalangan manajemen perusahaan adalah Decision Support System atau disingkat DSS. DSS ini merupakan suatu sistem informasi yang diharapkan dapat membantu manajemen dalam proses pengambilan keputusan. Hal yang perlu ditekankan di sini adalah bahwa keberadaan DSS bukan untuk menggantikan tugas tugas manajer, tetapi untuk menjadi sarana penunjang (tools) bagi mereka. DSS sebenarnya merupakan implementasi teoriteori pengambilan keputusan yang telah diperkenalkan oleh ilmu - ilmu seperti operation research dan management science. Hanya bedanya adalah bahwa jika dahulu untuk mencari penyelesaian masalah yang dihadapi harus dilakukan perhitungan iterasi secara manual (biasanya untuk mencari nilai minimum, maksimum, atau optimum), saat ini computer PC telah menawarkan kemampuannya untuk menyelesaikan persoalan yang sama dalam waktu relatif singkat. Dalam kedua bidang ilmu di atas, dikenal istilah decision modeling, decision theory, dan decision analysis - yang pada hakekatnya adalah merepresentasikan permasalahan manajemen yang dihadapi setiap hari ke dalam bentuk kuantitatif (misalnya dalam bentuk model matematika). Contoh contoh klasik dari persoalan dalam bidang ini adalah linear programming, game's theory, transportation problem, inventory system, decision tree, dan lain sebagainya. Dari sekian banyak problem klasik yang kerap dijumpai dalam aktivitas bisnis perusahaan sehari - hari, sebagian dapat dengan mudah disimulasikan dan diselesaikan dengan menggunakan formula atau rumus - rumus sederhana. Tetapi 
banyak pula masalahan yang ada sangat rumit sehingga membutuhkan kecanggihan komputer.

\section{LANDASAN TEORI}

Decision Support System (DSS) adalah sebuah sistem yang mampu memberikan kemampuan pemecahan masalah maupun kemampuan pengkomunikasian untuk masalah dengan kondisi semi terstruktur dan tak terstruktur. Sistem ini digunakan untuk membantu pengambilan keputusan dalam situasi semi terstruktur dan situasi yang tidak terstruktur, dimana tak seorangpun tahu secara pasti bagaimana keputusan seharusnya dibuat (Turban \& Aronson, 2001)

Decision Support System merupakan salah satu produk perangkat lunak yang dikembangkan secara khusus untuk membantu manajemen dalam proses pengambilan keputusan. Sesuai dengan namanya, tujuan dari dipergunakannya sistem ini adalah sebagai "second opinion" atau "information sources" yang dapat dipakai sebagai bahan pertimbangan sebelum seorang manajer memutuskan kebijakan tertentu. Pendekatan yang paling sering dilakukan dalam proses perancangan sebuah decision support system adalah dengan menggunakan teknik simulasi yang interaktif, sehingga selain dapat menarik minat manajer untuk menggunakannya, diharapkan system ini dapat merepresentasikan keadaan dunia nyata atau bisnis yang sebenarnya (Indrajit, 2013).

Decission support system sebagai sebuah sistem, memiliki lima karakteristik utama (Spargue \& Watson, 1993) :

1) Sistem yang berbasis komputer;

2) Dipergunakan untuk membantu para pengambil keputusan;

3) Untuk memecahkan masalah - masalah rumit yang "mustahil" dilakukan dengan kalkulasi manual;

4) Melalui cara simulasi yang interaktif;
5) Dimana data dan model analisis sebagai komponen utama.

\section{Classical Economic Order Quantity Model (EOQ Model)}

Economic Order Quantity (EOQ) adalah sebuah teknik kontrol persediaan yang meminimalkan biaya total dari pemesanan dan penyimpanan. Setiap perusahaan industri, dalam usahanya untuk melakukan proses produksinya yaitu dengan melakukan pembelian. Dalam melakukan pembelian bahan baku yang harus dibeli untuk memenuhi kebutuhan selama satu periode tertentu agar perusahaan tidak mengalami kekurangan bahan baku dan juga bisa mendapatkan bahan dengan biaya seminimal mungkin (Gani \& Saputri, 2015). Kebanyakan literatur persediaan mengatakan bahwa model Economic Order Quantity (EOQ) mudah untuk diterapkan apabila asumsi dalam Economic Order Quantity ( EOQ) dipenuhi, yaitu (Ristono, 2009) :

1. Hanya satu item barang yang diperhitungkan.

2. Laju permintaan diketahui.

3. Lead time atau waktu menunggu kedatangan bahan baku diketahui dan bersifat konstan.

4. Tidak ada pesanan ulang karena kehabisan persediaan

5. Kapasitas gudang dan modal cukup untuk menampung dan membeli pesanan.

6. Tidak ada quantity discount.

7. Biaya yang diperhitungkan adalah biaya pemesanan dan biaya penyimpanan.

Tujuan dari metode EOQ ini adalah untuk menentukan jumlah ekonomis setiap kali pemesanan sehingga meminimasi biaya total persediaan, dimana setiap melakukan pemesanan maka ada 2 macam biaya yang harus diperhatikan, yaitu biaya pemesanan dan biaya penyimpanan.

Implementasi EOQ menggunakan formula sebagai berikut (Cargal, 2003) :

$$
Q^{*}=\sqrt{\frac{2 D S}{H}}
$$


Dimana

$\mathrm{H}=$ holding cost per unit and time unit (Biaya simpan per unit sebagai sebagian kecil dari biaya produk)

$\mathrm{S}=$ ordering or setup cost (biaya pesanan produk. Ini adalah biaya tetap yang dikenakan untuk membuat pesanan apa pun dan apa adanya independen dari Q)

$\mathrm{D}=$ demand per time unit (permintaan tahunan produk dalam jumlah per unit waktu. Ini juga bisa diketahui sebagai tingkat)

$\mathrm{Q}=$ batch quantity (jumlah pesanan EOQ. Ini adalah variabel yang akan dioptimalkan. Yang lainnya variabel adalah jumlah tetap)

EOQ model harus memenuhi syarat (Haris, 1913):

1) Permintaan konstan dan kontinyu.

2) Ordering and holding costs konstan setiap waktu.

3) The batch quantity tidak harus integer.

4) Batch quantity dikirim pada saat yang sama.

5) Tidak diijinkan adanya shortages.

Salah satu hambatan bagi setiap manajer inventaris adalah terjadinya kekurangan inventaris (kadang-kadang disebut sebagai persediaan habis) permintaan yang tidak dapat dipenuhi saat ini karena persediaan habis. Ini menyebabkan berbagai kendala, termasuk berurusan dengan ketidakpuasan pelanggan dan memiliki pencatatan ekstra untuk mengatur pengisian permintaan nanti (pemesanan kembali) ketika persediaan dapat diisi ulang. Dengan asumsi bahwa kekurangan yang direncanakan tidak diperbolehkan, model EOQ klasik yang disajikan di atas memenuhi keinginan umum para manajer untuk sebisa mungkin menghindari kekurangan (meski demikian, kekurangan yang tidak direncanakan masih bias terjadi jika tingkat permintaan dan pengiriman tidak sesuai jadwal.) Namun, ada situasi di mana dimungkinkan terjadi kekurangan dar rencana yang ditolerir dari perspektif manajerial. Persyaratan yang paling penting adalah bahwa pelanggan pada umumnya dapat dan bersedia menerima penundaan dalam batas wajar dalam memenuhi pesanan mereka jika diperlukan.

Model EOQ dengan Planned Shortage mengatasi situasi semacam ini dengan hanya mengganti asumsi ketiga dari model EOQ klasik dengan asumsi ketika terjadi kekurangan, pelanggan bersedia menunggu produk tersedia kembali.

Sedangkan biaya Pesan Optimal adalah

$$
Q^{*}=\sqrt{\frac{2 D S}{H}\left[\frac{H+B}{B}\right]}
$$

Dimana

$\mathrm{D}=$ demand per time unit (permintaan tahunan produk dalam jumlah per unit waktu. Ini juga bisa diketahui sebagai tingkat)

$\mathrm{H}=$ holding cost per unit and time unit (Biaya simpan per unit sebagai sebagian kecil dari biaya produk)

$S=$ ordering or setup cost (biaya pesanan produk. Ini adalah biaya tetap yang dikenakan untuk membuat pesanan apa pun dan apa adanya independen dari Q)

$\mathrm{B}=$ shortage cost per unit short per unit of time short

$\mathrm{Q}=$ batch quantity (jumlah pesanan EOQ. Ini adalah variabel yang akan dioptimalkan. Yang lainnya variabel adalah jumlah tetap)

\section{METODE}

Metode yang digunakan adalah perancangan sistem menggunakan Microsoft Visual Basic untuk mendukung keputusan dalam menghitung jumlah persediaan agar menjadi optimal

\section{PEMBAHASAN}

Komponen Perhitungan Model-Model Inventory yang digunakan antara lain ;

\section{Biaya (costs)}

1) Holding Costs

a) Opportunity cost for capital tied up in inventory 
b) Material handling costs

c) Costs for storage

d) Costs for damage and obsolescence

e) Insurance costs

f) Taxes

2) Ordering or Setup Costs
a) setup and learning
b) administrative costs associated with the
c) handling of orders
d) transportation and material handling.

3) Shortage Costs or Service Constraints
a) extra costs for administration
b) price discounts for late deliveries
c) material handling and transportation

\section{Inventory position}

Inventory position $=$ stock on hand + outstanding orders - backorders.

Inventory level $=$ stock on hand backorders.

\section{Pengecekan secara kontinyu atau} periodic (Continuous or Periodic Review)

Pada saat posisi inventory menipis, memicu proses pemesanan. Hal ini kita sebut sebagai continuous review.

$\mathrm{L}=$ lead-time.

$\mathrm{T}=$ periode pengecekan (review period) seperti jarak waktu pengecekan (the time interval between reviews).

Different Preordering Policies

$(\mathrm{R}, \mathrm{Q})$ policy

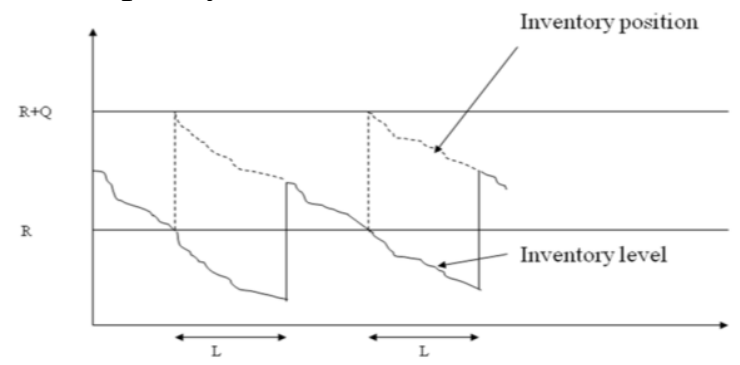

Gambar $1(\mathrm{R}, \mathrm{Q})$ policy with continuous review. Permintaan Kontinyu (Continuous demand).

Ketika posisi inventory mendekati reorder point $\mathrm{R}$, batch quantity sejumlah $\mathrm{Q}$ dipesan.

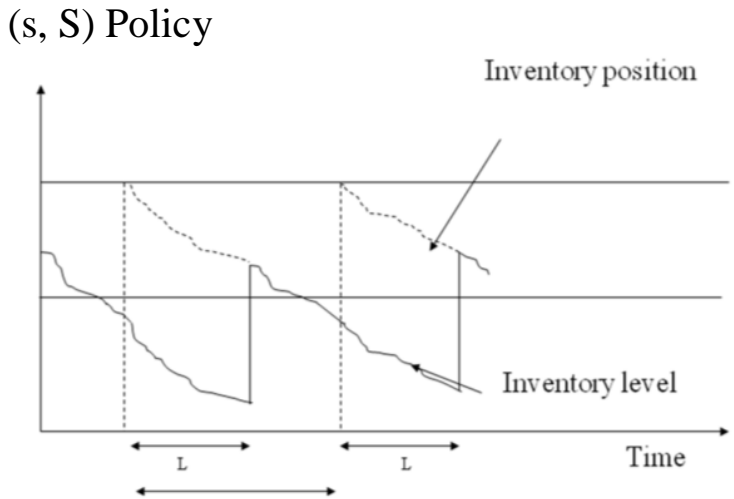

Gambar 2 (s, S) policy, periodic review. Ketika posisi inventory mendekati s, dilakukan pemesanan sampai level maksimum $\mathrm{S}$.

\section{Classical Economic Order Quantity Model (EOQ Model)}

Menurut Harris (1913), EOQ model harus memenuhi syarat :

1) Permintaan konstan dan kontinyu.

2) Ordering and holding costs konstan setiap waktu.

3) The batch quantity tidak harus integer.

4) Batch quantity dikirim pada saat yang sama.

5) Tidak diijinkan adanya shortages.

\section{Notasi yang digunakan :}

$\mathrm{H}=$ holding cost per unit and time unit

$\mathrm{S}=$ ordering or setup cost

$\mathrm{D}=$ demand per time unit

$\mathrm{Q}=$ batch quantity

$\mathrm{C}=$ costs per time unit

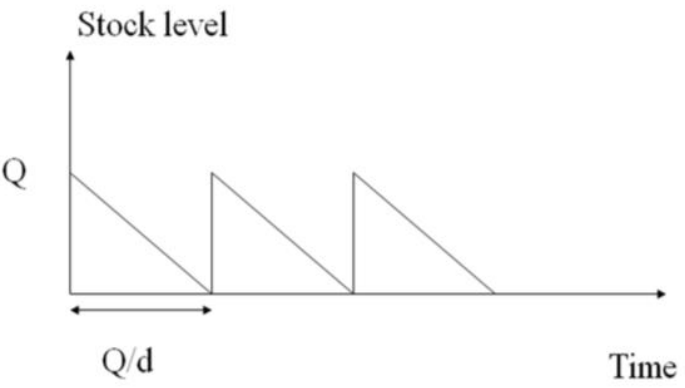

Gambar 3 Development of inventory level over time.

$$
\begin{aligned}
& C=\frac{Q}{2} H+\frac{d}{Q} S \\
& \frac{d C}{d Q}=\frac{H}{2}-\frac{D}{Q^{2}} S=0
\end{aligned}
$$




$$
\begin{gathered}
Q^{*}=\sqrt{\frac{2 S D}{H}} \\
C^{*}=\sqrt{\frac{S D H}{2}}+\sqrt{\frac{S D H}{2}}=\sqrt{2 S D H}
\end{gathered}
$$

Dari (1), (3) dan (4) diperoleh quatity order optimal :

$\frac{C}{C^{*}}=\frac{Q}{2} \sqrt{\frac{H}{2 S D}}+\frac{1}{2 Q} \sqrt{\frac{2 S D}{H}}=\frac{1}{2}\left(\frac{Q}{Q^{*}}+\frac{Q^{*}}{Q}\right)$

Tampilan Program :

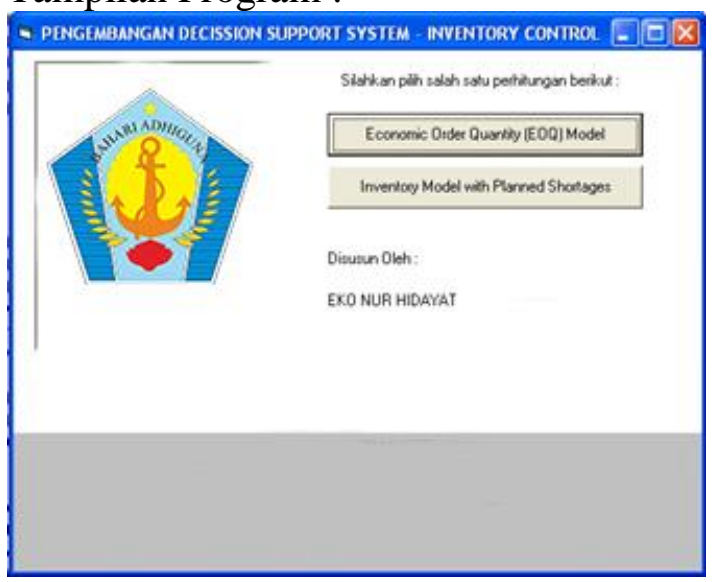

Gambar 4 : tampilan menu utama

Pada saat dipilih EOQ Model akan muncul :

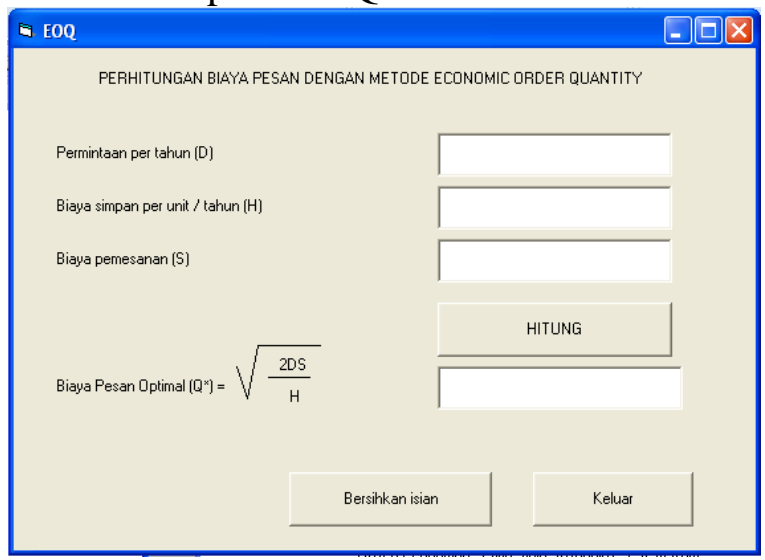

Gambar 5 : Tampilan EOQ klasik

Validasi yang diberikan untuk form EOQ adalah :

1. Semua isian hanya boleh diisi angka (tidak boleh huruf)
2. Biaya simpan per tahun $(\mathrm{H})$ tidak boleh diisi nol, karena akan mengakibatkan hasil perhitungan terjadi pembagian dengan nol (tidak terdefinisi)

3. Semua isian harus diisi

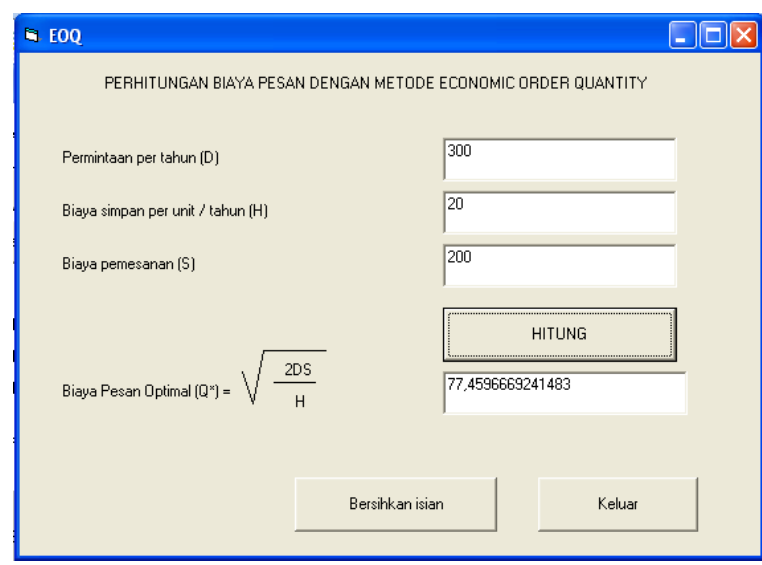

Gambar 6 : hasil perhitungan dengan EOQ klasik

Sedangkan jika dipilih Inventory Model with Planned Shortages akan muncul :

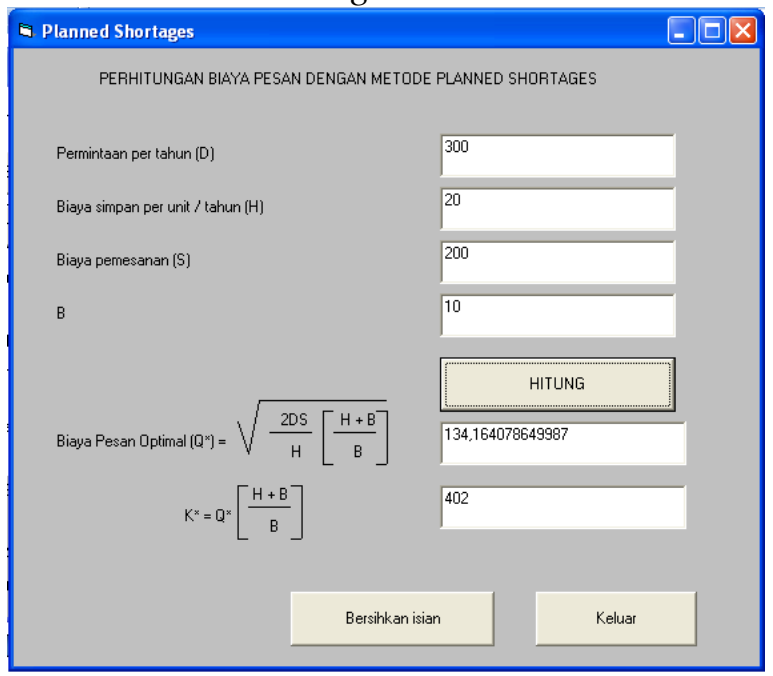

Gambar 7 : hasil perhitungan dengan Model with Planned Shortages

Validasi yang diberikan untuk form shortages adalah :

1. Semua isian hanya boleh diisi angka (tidak boleh huruf)

2. Biaya simpan per tahun $(\mathrm{H})$ dan nilai $B$ tidak boleh diisi nol, karena akan mengakibatkan hasil perhitungan terjadi pembagian dengan nol (tidak terdefinisi)

3. Semua isian harus diisi 
Listing Program :

Form Menuutama

Private Sub cmdeoq_Click()

Load eoq

eoq.Show

menuutama.Enabled $=$ False

End Sub

Private Sub cmdplanned_Click()

Load shortages

shortages.Show

menuutama.Enabled $=$ False

End Sub

\section{Form EOQ}

Private Sub cmdkeluar_Click() Unload Me

End Sub

Private Sub Command1_Click()

If Text1.Text $=$ "" Then

$\mathrm{x}=\operatorname{MsgBox}($ "Permintaan harus

diisi dahulu...", vbCritical,

"Perhatian")

Text1.SetFocus

ElseIf Text2.Text $=$ "" Then

$\mathrm{x}=\operatorname{MsgBox}($ "Biaya simpan per

unit / tahun harus diisi dahulu...",

vbCritical, "Perhatian")

Text2.SetFocus

ElseIf Text3.Text $=$ "" Then

$\mathrm{x}=\operatorname{MsgBox}($ "biaya pemesanan

harus diisi dahulu ...", vbCritical,

"Perhatian")

Text3.SetFocus

Else

Text4. Text $=\operatorname{Sqr}(2 *$

$\operatorname{Val}($ Text1.Text $) * \operatorname{Val}($ Text3.Text $) /$

$\operatorname{Val}($ Text2.Text))

End If

End Sub

Private Sub Command2_Click()

Text1.Text $=" "$

Text2.Text $=" "$

Text3.Text $=" "$

Text4.Text $=" "$

Text1.SetFocus

End Sub
Private Sub Form_Unload(Cancel

As Integer)

menuutama.Enabled $=$ True

menuutama.SetFocus

End Sub

Private Sub

Text1_KeyPress(KeyAscii As

Integer)

If $($ KeyAscii < 48 Or KeyAscii >

57) And KeyAscii $\gg$ vbKeyBack

Then

$\mathrm{x}=\operatorname{MsgBox}($ "Isian ini hanya

boleh diisi angka...", vbOKOnly,

"Perhatian")

KeyAscii $=0$

End If

End Sub

Private Sub

Text2_KeyPress(KeyAscii As

Integer)

If $($ KeyAscii $<48$ Or KeyAscii >

57) And KeyAscii <> vbKeyBack

Then

$\mathrm{x}=\mathrm{MsgBox}($ "Isian ini hanya

boleh diisi angka...", vbOKOnly,

"Perhatian")

KeyAscii $=0$

End If

End Sub

Private Sub

Text3_KeyPress(KeyAscii As

Integer)

If KeyAscii < 48 Or KeyAscii >

57 And KeyAscii 〈> vbKeyBack

Then

$\mathrm{x}=\operatorname{MsgBox}($ "Isian ini hanya boleh diisi angka...", vbOKOnly, "Perhatian")

KeyAscii $=0$

End If

End Sub

Form shortages

Private Sub cmdkeluar_Click()

Unload Me

End Sub 


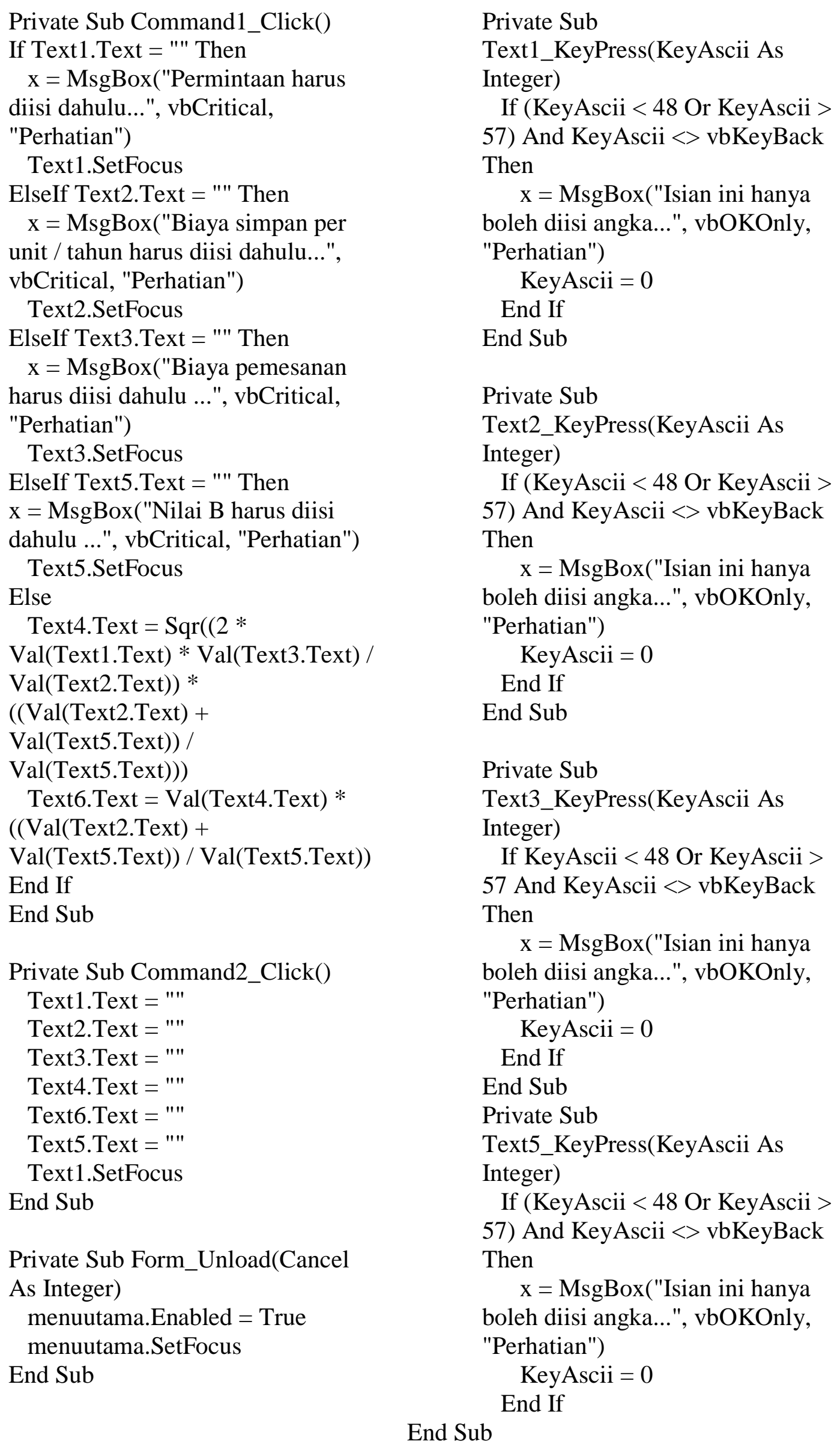




\section{KESIMPULAN}

Dengan menggunakan sistem pendukung keputusan, beberapa kesalahan terkait dengan pencatatan data pada pengadaan dan ketidakakuratan dalam menentukan jumlah persediaan dapat dikurangi sehingga perusahaan dapat menghindari kerugian material.

\section{DAFTAR PUSTAKA}

Cargal, J. (2003). the EOQ Inventory Formula, Mathematical Sciences, 1.31, Ed. Retrieved September 1, 2020, from the EOQ Inventory Formula, Mathematical Sciences, 1.31 , Ed.: http://www.cargalmathbooks.com/T he\%20EOQ\%20Formula.pdf

Efraim, T., Ephraim, M., \& James, W. (1999). Information Technology for Management : Making Connections for Strategic Advantage second edition. New York: John Wiley \& Sons, Inc.

Gani, I. M., \& Saputri, M. E. (2015). Analisis Peramalan dan
Pengendalan Persediaan Bahan Baku dengan Metode EOQ pada Optimalisasi Kayu di Perusahaan Purezento. e-Proceeding of Management, 1 - 10.

Haris, F. W. (1913). "How many parts to make at once". Factory, the Magazine of Management., 135136, 152.

Indrajit, R. E. (2013, February 9). Decision Support System. Seri 999 E-Artikel Sistem dan Teknologi Informasi, p. 2.

Ristono, A. (2009). Manajemen Persediaan. Yogyakarta: Graha Ilmu.

Spargue, R. H., \& Watson, H. J. (1993). Decision Support Systems: Putting Theory Into Practice. Englewood Clifts, N. J: Prentice Hall.

Turban, E., \& Aronson, J. (2001). Decision Support Systems and Intelligent Systems. 6th edition. Upper Saddle River, NJ: Prentice Hall. 